\title{
DEVELOPMENT OF AN ON-LINE COAL WASHABILITY ANALYZER
}

\section{Report Type: SEMI-ANNUAL}

Principal Author(s): Jan D. Miller

C. L. Lin

G.H. Luttrell

G.T. Adel

Report Issue Date: 03/31/1999

DOE Award No.: DE- FG22 -96PC96215--05

\section{University of Utah}

Submitting

Organization(s)

Department of Metallurgical Engineering

Name \& Address

135 S 1460 E Rm 412

Salt Lake City, Utah 84112

Virginia Polytecnic Institute and State University

Department of Mining and Mineral Engineering

100 Holden Hall, Virginia Tech

Blacksburg, Virginia 24061 
Project Title

DEVELOPMENT OF AN ON-LINE COAL WASHABILITY ANALYZER

Semi-Annual Report

$(10 / 01 / 1998-03 / 31 / 1999)$

DOE award No. : DE-FG22-96PC96215

\section{Principal Investigator:}

J. D. Miller, Professor, Department of Metallurgical Engineering, University of Utah.

\section{Co-Principal Investigators:}

G. H. Luttrell, Professor, Department of Mining and Minerals Engineering, Virginia Polytechnic Institute and State University.

G. T. Adel, Professor, Department of Mining and Minerals Engineering, Virginia Polytechnic Institute and State University.

C. L. Lin, Research Associate Professor, Department of Metallurgical Engineering, University of Utah.

Barbara Marin, Geologist, Terra Tek. Salt Lake City, Utah.

David Brafford, General Manager, Northland Resources, Mingo County, Delbarton, West Virginia. 


\section{TABLE OF CONTENTS}

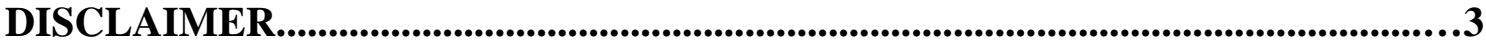

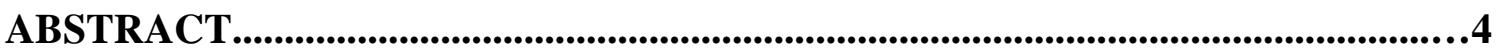

EXECUTIVE SUMMARY ..........................................................................................5

RESULTS AND DISCUSSION (by tasks).....................................................................5

SUMMARY STATUS ASSESSMENT AND FORECAST .........................................6 


\section{DISCLAIMER}

This report was prepared as an account to work sponsored by an agency of the United States Government. Neither the United States Government nor any agency thereof, nor any of their employees, makes any warranty, express or implied, or assumes any legal liability or responsibility for the accuracy, completeness, or usefulness of any information, apparatus, product, or process disclosed, or represents that its use would not infringe privately owned rights. Reference herein to any specific commercial product, process, or service by trade name, trademark, manufacturer, or otherwise does not necessarily constitute or imply its endorsement, recommendation, or favoring by the United States Government or any agency thereof. The views and opinions of authors expressed herein do not necessarily state or reflect those of the United States Government or any agency thereof. 


\begin{abstract}
Washability analysis is the basis for nearly all coal preparation plant separations. Unfortunately, there are no on-line techniques for determining this most fundamental of all coal cleaning information. In light of recent successes at the University of Utah, it now appears possible to determine coal washability on-line through the use of x-ray computed tomography (CT) analysis. The successful development of such a device is critical to the establishment of process control and automated coal blending systems. In this regard, Virginia Tech, Terra Tek Inc., and several eastern coal companies have joined with the University of Utah and agreed to undertake the development of a x-ray CT-based on-line coal washability analyzer with financial assistance from DOE. The three-year project will cost $\$ 594,571$, of which $33 \%(\$ 194,575)$ will be cost-shared by the participants. The project involves development of appropriate software and extensive testing/evaluation of well-characterized coal samples from operating coal preparation plants. Each project participant brings special expertise to the project which is expected to create a new dimension in coal cleaning technology. Finally, it should be noted that the analyzer may prove to be a universal analyzer capable of providing not only washability analysis, but also particle size distribution analysis, ash analysis and perhaps pyritic sulfur analysis.
\end{abstract}




\section{EXECUTIVE SUMMARY}

The primary objective of the proposed research program is to develop a CT-based, online coal washability analyzer. A secondary objective will be to demonstrate the capabilities of the analyzer by comparing efficiency data from traditional float-sink tests conducted at three preparation plant sites with efficiency data generated by the washability analyzer. The scope of the proposed research program involves several tasks including (i) the acquisition and preparation of test samples for use in testing and calibrating the analyzer, (ii) the development of appropriate hardware and software necessary to adapt a CT analyzer for use in determining coal washability, (iii) the testing and modification of the analyzer using wellcharacterized coal samples, (iv) the evaluation of the analyzer's performance under simulated plant conditions, and (v) an evaluation of the technical and economic feasibility of implementing the CT-based washability analyzer on a commercial basis.

Researchers from the University of Utah and Terra Tek Inc. will perform tasks related to the development, calibration and testing the analyzer, while technical personnel from Virginia Tech and Cyprus Amax will provide the required coal samples, evaluate the industrial capabilities of the analyzer, and promote system commercialization.

The main effort during this reporting period involved waahability analysis for selected samples ( $2 \times 1$ inch and $1 \times 1 / 2$ inch) composed from size/density fraction of sink-float tests. To facilitate the washability analysis using x-ray CT, an integrated software system is being developed to process sequential CT data sets.

\section{RESULTS AND DISCUSSION (by task)}

\section{$\underline{\text { Task 1. Project Management }}$}

Two graduate students (Ataullah Mirza-Baig and Altaf Khan) at the University of Utah were assigned to the project to coordinate the CT scanning for washability analysis, and to develop software and hardware. At Virginia Tech, two additional graduate students (David Brafford and Jaisen Kohmuench) have been assigned to work part-time on this project to acquire coal samples, perform characterization tests and collect field data used to evaluate the industrial applications of the proposed technology.

\section{Task 4. Software Development}

When dealing with large 2-D CT data sets, a software system designed with a graphical user interface (GUI) will allow the user to handle the coal washability analysis easily. In this regard, an integrated software system was developed which allows the user to download the sequence of the original 2-D CT data sets (in 2-byte format). The system facilitates the separation and classification of particle images in order to obtain the washability analysis. 
One of the important functions of the GUI is to deal with the user input, which can be a keystroke or a mouse action. User input is often referred to as an event. The main components of the implemented GUI include the graphical icons and the event-control subroutines. Figure 1 shows the layout of the GUI used for the development of this integrated image processing and analysis system. The main menu lets the user select the subroutines to be operated. The 2-D mass density analysis algorithm, reported previously, is implemented as one of the subroutines. As shown in Figure 2, parameters can be set to handle various image format. For washability analysis with the use of multiple CT images, parameters can be set as shown in Figure 3.

\section{Task 6. Testing/Modification}

The experimental test program is in progress to evaluate the CT scanner using coal samples prepared under carefully-controlled laboratory conditions. The test program is subdivided into four separate series of tests, single size/single gravity, single size/multiple gravity, multiple size/single gravity, and multiple size/multiple gravity.

Two samples, single size/multiple density ( $2 \times 1$ inch and $1 \times 1 / 2$ inch), were prepared for washability analysis using x-ray CT techniques. Using plastic containers as the sample chamber, two sets of sequential cross sectional images (150 and 124 slices) were collected. In these experiments each 2-D CT slice is $2 \mathrm{~mm}$ in thickness. Washability data for these carefully prepared samples are shown in Tables 1 and 2, respectively. Washability curves for both samples using sink-float data are constructed and shown in Figures 4 and 5 respectively. In addition to the primary washability curve, three related curves, namely, specific gravity/yield curve, clean coal and reject curves for ash are also included for both coal samples.

Based on the 2-D CT images (slices) of these coal particle beds, Figures 6 and 7 illustrate the constructed specific gravity/yield curves for size fractions, $2 \times 1$ and $1 \times 1 / 2$ inch, respectively. The specific gravity/yield curves for both samples using sink-float tests (Figures 4 and 5) are included for comparison. Good agreement is observed for both samples.

. Characteristics of the washability based on ash content of the particle population will be determined once the detailed relationship between ash content and specific gravity is established.

\section{SUMMARY STATUS ASSESSMENT AND FORECAST}

1. An integrated software system with graphical user interface (GUI) was developed which allows the user to download the sequence of the original 2-D CT image slices (in 2-byte format). This system facilitates the separation and classification of particle images in order to obtain the washability analysis. The 2-D mass density analysis algorithm, reported previously, is implemented as one of the subroutines. 
2. Two single size/multiple density samples were prepared to evaluate the washability analysis using the $\mathrm{x}$-ray CT technique. Using the algorithm for the 2-D mass density distribution analysis and the developed integrated software system, 150 and 124 slices of CT images were analyzed. The results indicate that the specific gravity/yield curves can be constructed using x-ray CT technique with good agreement with the data obtained from sink-float tests.

3. Characteristics of the washability based on ash content of the particle population is in progress. Preliminary results indicate that the washability curve based on ash content of coal particles can be estimated once the relationship between ash content and specific gravity is established. 
Table 1. Sink-float analyses for the Stockton coal sample ( 2 x 1 inch).

\begin{tabular}{|c|c|c|c|c|c|c|c|}
\hline \multicolumn{2}{|c|}{ Specific Gravity } & \multicolumn{3}{|c|}{ Individual Basis } & \multicolumn{3}{c|}{ Cumulative Basis } \\
\hline Sink & Float & Mass (\%) & Ash (\%) & Unit & Mass(\%) & unit & Ash(\%) \\
\hline \multirow{3}{*}{1.30} & 1.30 & 21.61 & 2.89 & 62.4 & 21.61 & 62.4 & 2.89 \\
1.40 & 1.40 & 19.46 & 10.73 & 208.8 & 41.07 & 271.2 & 6.60 \\
1.50 & 1.50 & 17.78 & 21.55 & 383.2 & 58.85 & 654.4 & 11.12 \\
1.60 & 1.60 & 5.39 & 28.32 & 152.6 & 64.24 & 807.1 & 12.56 \\
2.10 & 1.80 & 3.23 & 41.27 & 133.3 & 67.47 & 940.4 & 13.93 \\
& & 32.54 & 84.11 & 2736.9 & 100.0 & 3677.3 & 36.77 \\
\hline
\end{tabular}

Table 2. Sink-float analyses for the Stockton coal sample (1 x 1/2 inch).

\begin{tabular}{|c|c|c|c|c|c|c|c|}
\hline \multicolumn{2}{|c|}{ Specific Gravity } & \multicolumn{3}{c|}{ Individual Basis } & \multicolumn{3}{c|}{ Cumulative Basis } \\
\hline Sink & Float & Mass (\%) & Ash (\%) & Unit & Mass(\%) & unit & Ash(\%) \\
\hline \multirow{3}{*}{1.30} & 1.30 & 26.40 & 3.14 & 82.9 & 26.40 & 82.9 & 3.14 \\
1.40 & 1.40 & 21.10 & 10.10 & 213.1 & 47.50 & 296.0 & 6.23 \\
1.50 & 1.50 & 15.83 & 23.16 & 366.6 & 63.33 & 662.6 & 11.46 \\
1.60 & 1.60 & 6.59 & 29.06 & 191.5 & 69.92 & 854.1 & 12.22 \\
1.80 & 2.10 & 1.85 & 42.32 & 78.3 & 71.77 & 932.5 & 12.99 \\
2.10 & & 26.38 & 86.48 & 2281.3 & 100.0 & 3223.1 & 33.23 \\
\hline & & 100.00 & & & & & \\
\hline
\end{tabular}




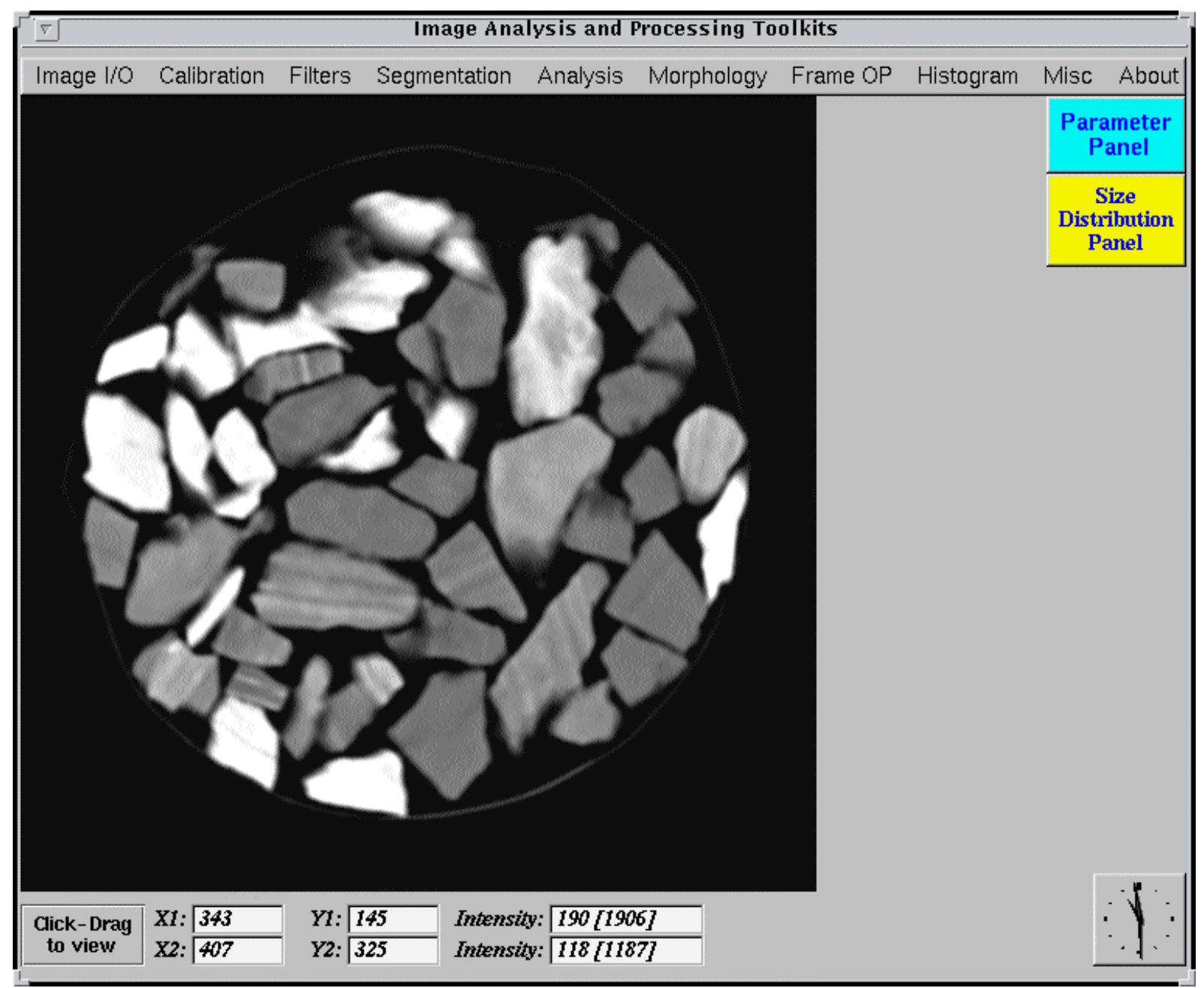

Figure 1. Layout of the graphical user interface (GUI) for the integrated image processing and analysis system for washability analysis of x-ray CT images. 


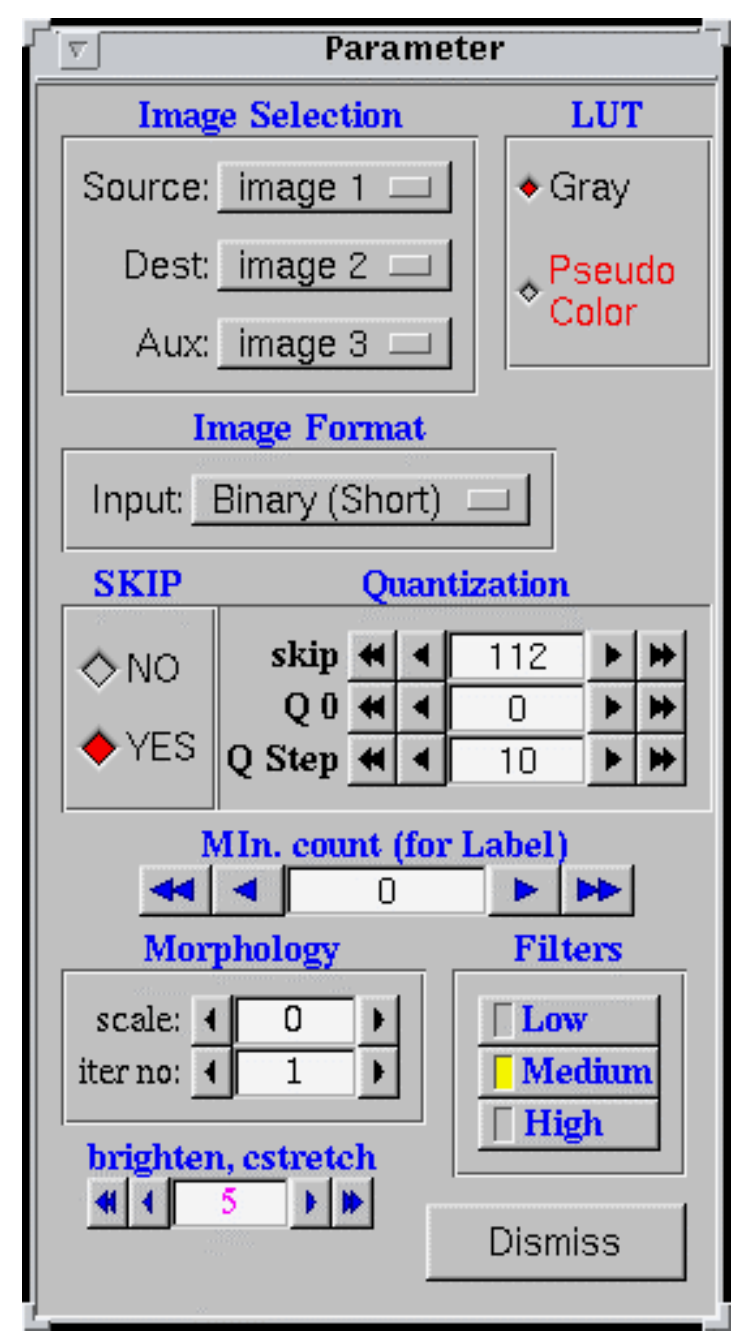

Figure 2. Parameter-window allows user to set the desired options. 


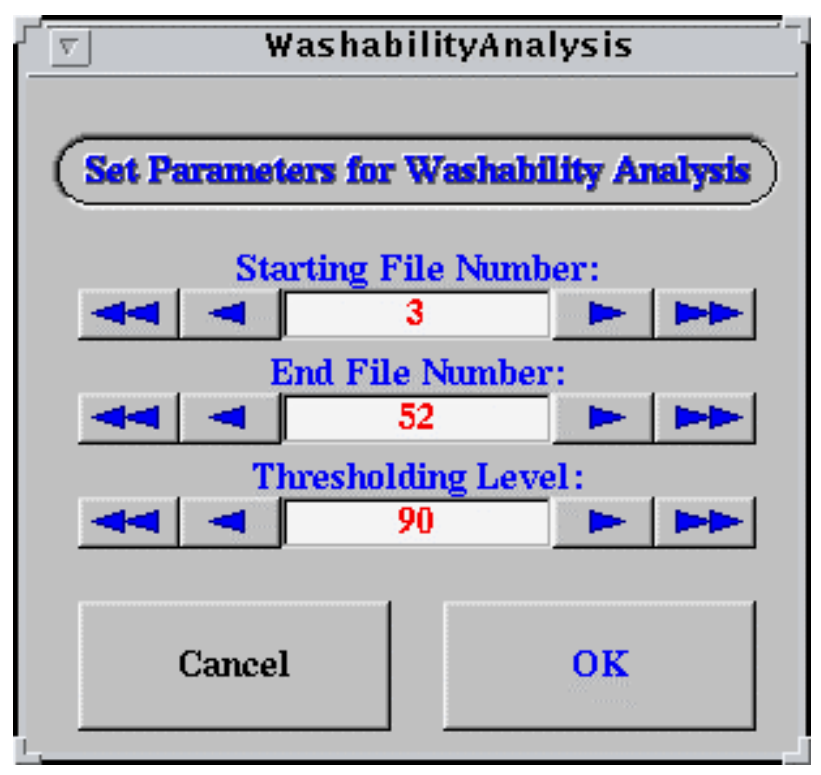

Figure 3. Sub-windows used for setting parameters for washability analysis for multiple CT images. 


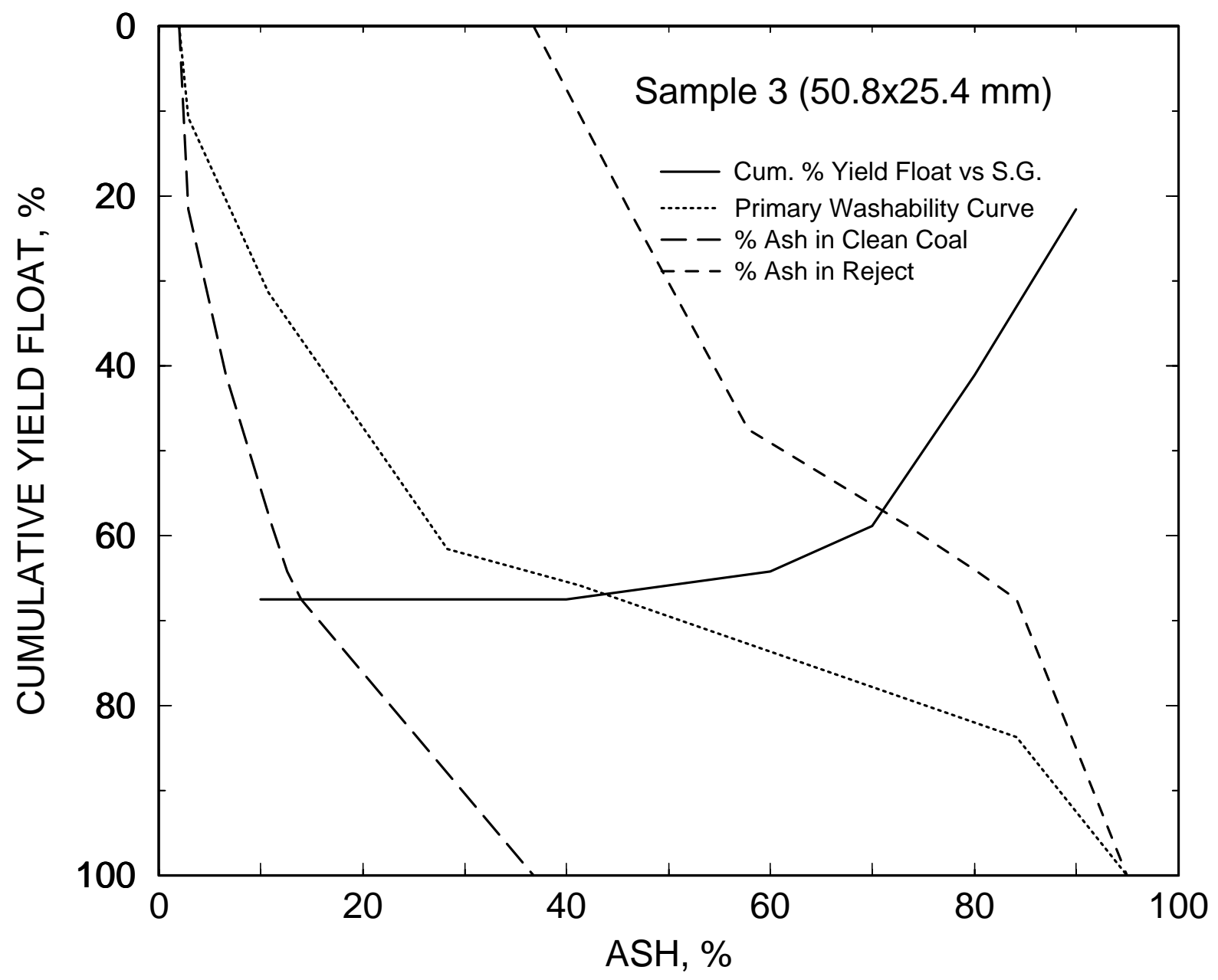

\section{$\begin{array}{lllllllllll}2.2 & 2.1 & 2.0 & 1.9 & 1.8 & 1.7 & 1.6 & 1.5 & 1.4 & 1.3 & 1.2\end{array}$ RELATIVE DENSITY}

Figure 4. Washability curves for $2 \times 1$ inch $(50.4 \times 25.4 \mathrm{~mm})$ coal sample. 

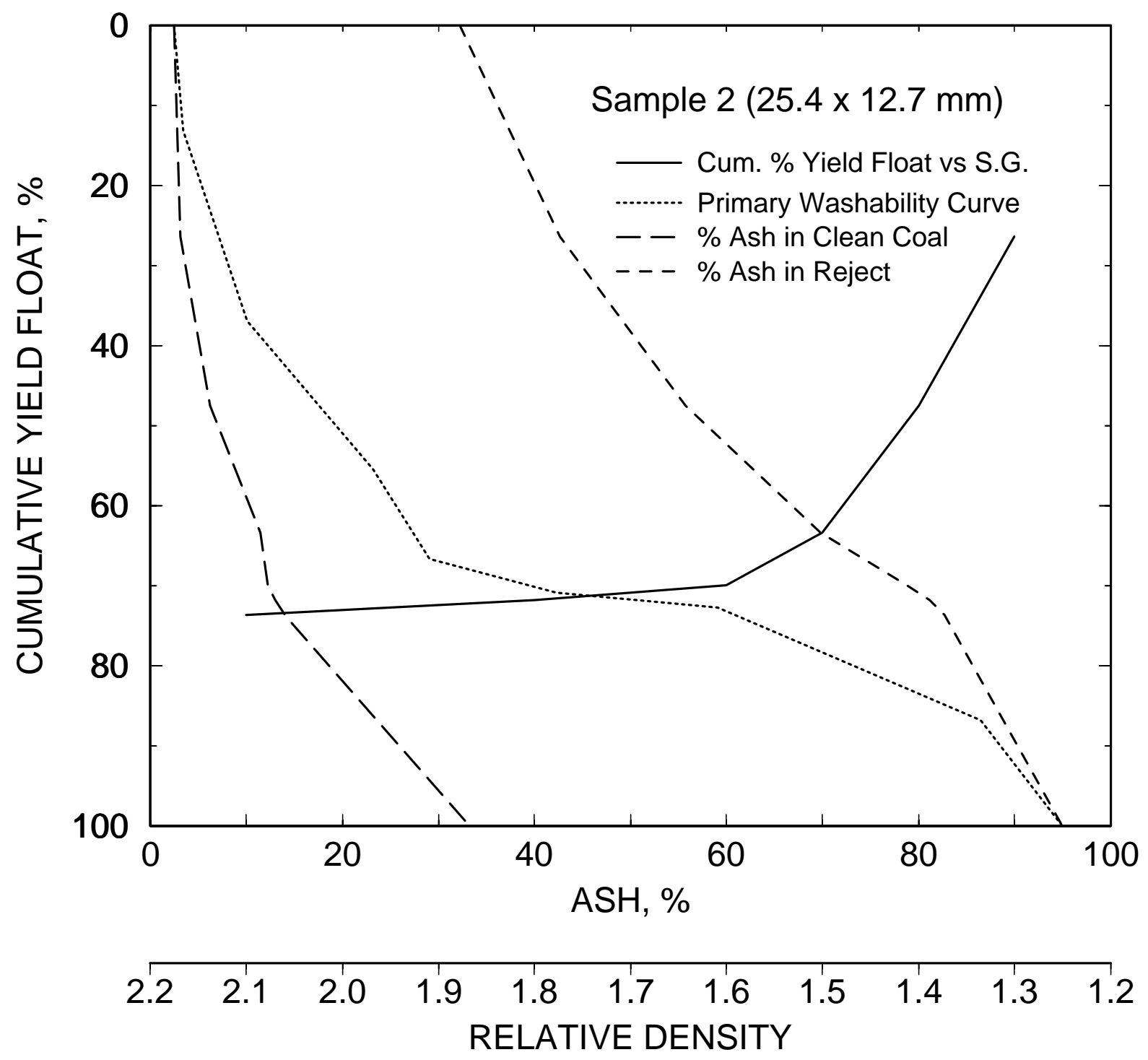

Figure 5. Washability curves for $1 \times 1 / 2$ inch $(25.4 \times 12.7 \mathrm{~mm})$ coal sample. 


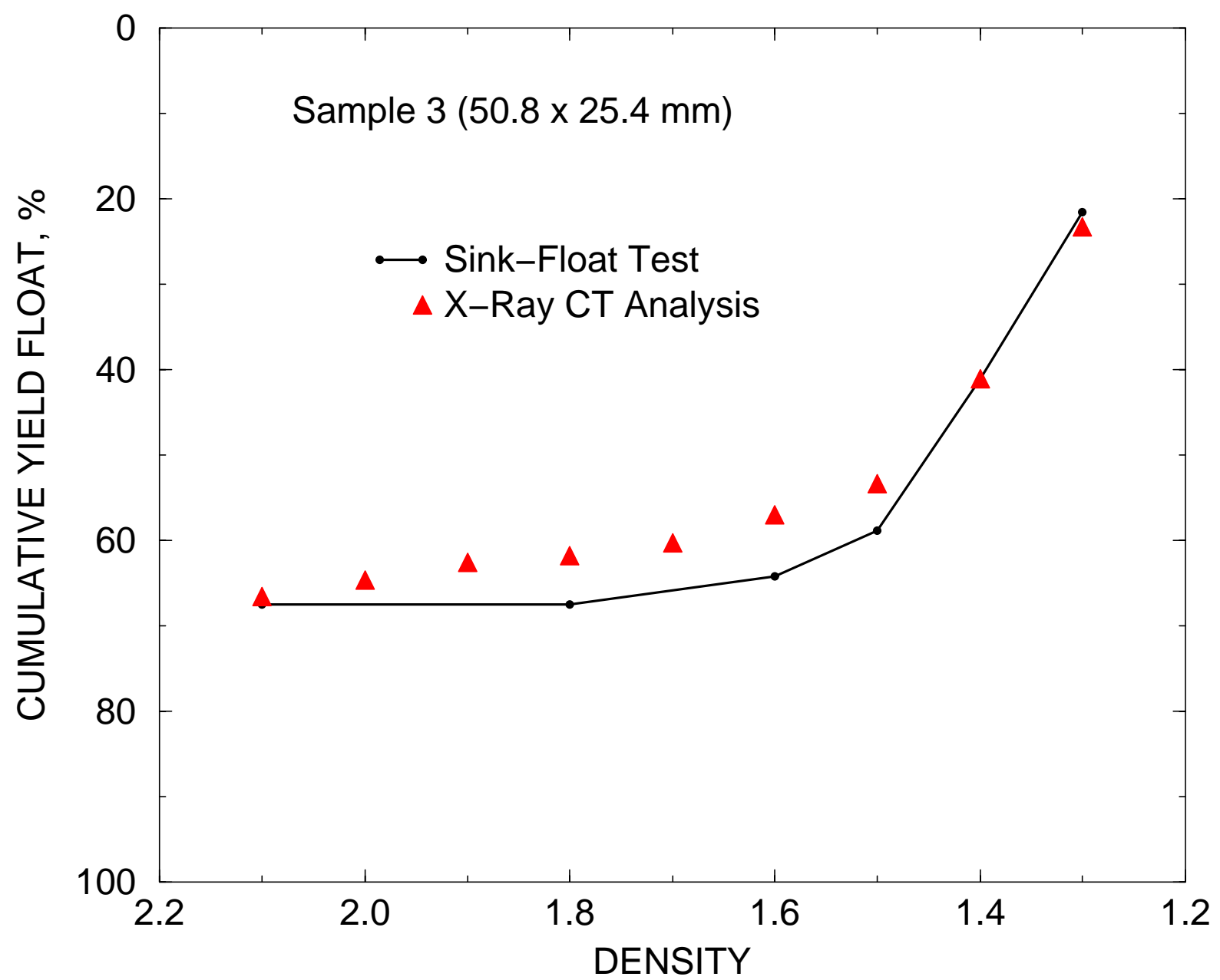

Figure 6. Comparison of specific gravity/yield curves for sample 3 using x-ray CT technique and sink-float test. 


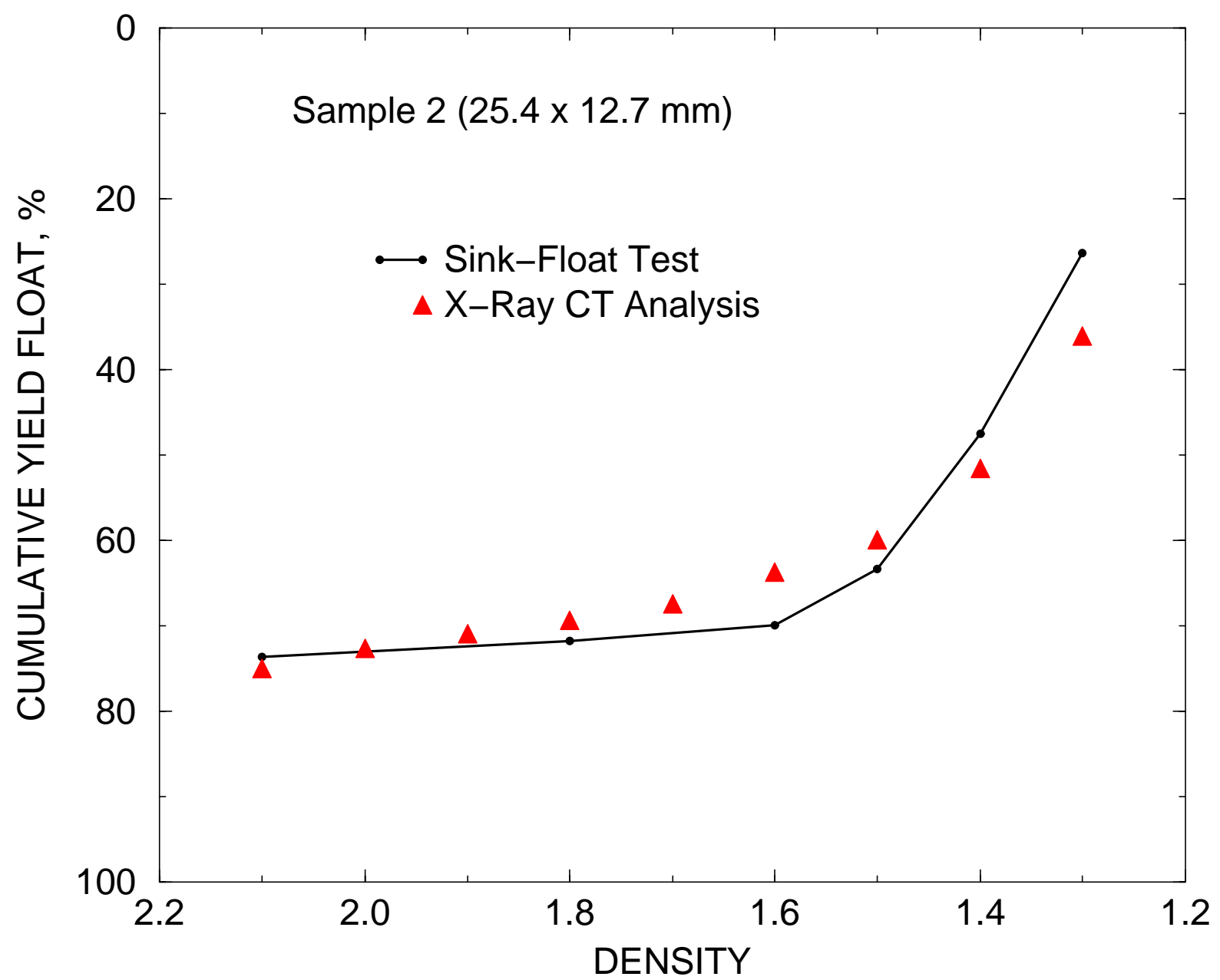

Figure 7. Comparison of specific gravity/yield curves for sample 2 using x-ray CT technique and sink-float test. 